G. Locatelli, M. Mancini "Risk management in a mega-project: the Universal EXPO 2015 Case" International Journal of Project Organisation and Management. 2010, Vol. 2, No.3 pp. 236 - 253.

\title{
Risk management in a mega-project: the Universal EXPO 2015 Case.
}

\author{
Giorgio Locatelli \\ Department of Management, Economics \& Industrial Engineering \\ Politecnico di Milano \\ Piazza Leonardo da Vinci, 32 \\ 20133 Milano - Italy \\ Tel: +3902.2399 .4056$ \\ Fax: +390223994083 \\ email: giorgio.locatelli@polimi.it \\ Mauro Mancini \\ Department of Management, Economics \& Industrial Engineering \\ Politecnico di Milano \\ Piazza Leonardo da Vinci, 32 \\ 20133 Milano - Italy \\ Tel: +39 02.2399.4065 \\ Fax: +3902 23994083 \\ email: mauro.mancini@polimi.it
}




\begin{abstract}
The paper analyzes the literature on risk management in mega-projects suggesting possible mitigation actions to be considered in the stakeholders management. EXPO 2015 represents a perfect project to understand the strength of a rigorous methodological approach to uncertainty and the need for a mature consciousness at managerial level on these topics. Analyzing real available data on this project, the number of visitors appears overestimated, so, adopting the SHAMPU framework, the paper quantifies the relative impact and provides possible mitigation actions. Practical actions crossing the risk management phases in mega projects proposed by literature are suggested in the conclusions.
\end{abstract}

Keywords: mega-projects, EXPO 2015, risk management, optimism bias. 


\section{Mega-projects: literature review}

\subsection{Introduction to mega-projects}

The literature defines "mega-project" a multi major infrastructure project with a value greater than $\$ 1$ billion (Flyvbjerg et al., 2003), usually commissioned by government and implemented by private enterprises, characterized by uncertainty, complexity and political sensitivity. It involves a wide range of business partners, industry, politicians (Clegg et al., 2002), and has strong economic and environmental impact for a long time (Bruzelius et al., 2002). Often a Mega-project can be seen as a set of different smaller projects with different contents, but coordinated to achieve a goal and a common result. Each of these projects is also characterized by elements of a mega-project such as complexity, uncertainty, integration of different skills in the organization, coordination of construction activities etc. (Van Marrewijk, 2008). Usually the public is the main backer in mega-projects, because public events (e.g. Olympics Games) have the strongest impact on urban development and economic areas. Moreover this kind of projects are the most strategic and require a huge financial effort. This usually implies a strong involvement from public institutions in the project financing phase.

This context generally drives the importance of the critical success factors, even in high engineering projects, from technical solutions to stakeholders management, both before and during the project development. Considering mega events like Olympic Games or Universal Expositions this element is furthermore increased by the mixture of social interests continuously changing in the short and long term that can completely modify the perception of the performance of the project. This generally allows for a clear picture of the project only after decades (remember for instance that the Eiffel Tower was built for the 1889 EXPO in Paris) which imposes a rigorous approach to project uncertainties in order to take opportunities that could be lost without a precise balance of positive and negative impacts.

The huge amount of studies proposed by international literature generally focused on the analysis of past events, i.e. on what had gone in the right or in the wrong direction, trying to summarise the lessons learned for the future. This kind of studies are very important, but, obviously, they do not take into consideration those projects that never got started due to negative output of risk analysis, and so it is very difficult to measure lost opportunities. This paper will try to cover this gap suggesting a correct approach in the determination of the positive and negative impact of stakeholder pressure on a mega project (that lead to a demand overestimation) enlarging the spectrum of possible mitigation action to be considered in order to avoid the loss of good opportunities for the companies and communities involved.

Based on the public data from the bid dossier (http://www.milanoexpo-2015.com.) this paper deals with the following research question: "Has demand been overestimated in the EXPO 2015 case and, if so, what will its effect be and how is it possible to reduce unsought outcomes?". Therefore, this work fits in the stream of "risk of demand in a mega-project", but with respect to most of the paper of this stream (reported in the literature section) this is an 'a priori' evaluation and not an 'ex-post'. In fact, we aim to assess if the estimation of the number of visitors and visits (a visitor can make multiple visits.) is reliable, before the event and not after. We think that this analysis is extremely valuable, because we are in the planning phase of this project, therefore it is possible to implement all the corrective actions necessary for the project success. 


\subsection{Project Risk management in mega events}

As Flyvbjerg observes (Flyvbjerg et al., 2002, 2003), the risks characterizing a mega-project can be clustered in four areas:

1. Risks of cost (construction, maintenance, management);

2. Risks of demand (income and estimated demand);

3. Financial risks and market (lack of funds, financial sustainability, interest rates);

4. Political risks (regulatory, public investment parallel).

The breakdown of risks into areas or sources or typology and so on, as proposed by literature and actually applied by companies, is very useful to define mitigation actions and, in fact, in this paper we deal exclusively with the second point. But this can also be misleading because it can lead to difficulty or to an underestimation in the correlations among factors, that generates uncertainty on the project. The main consequence is that, especially on mega events, since the bigger amount of analyses generally considers the negative risk (to protect the organization committee) some opportunities may be lost and cannot be rightly balanced by the optimistic perception of some stakeholders. On this idea the contribution of Warrack (Warrack 1985; 1993) must be stressed because, recognising as a critical factor for a megaproject the strong involvement of public actors in its financing and governance, he poses as a pre-requisite that a public management should have the decision-making power and ability to guide the design choices to overcome problems and obtain the financial and social benefits developing a good project culture involving all the stakeholders. So, no mistake can be allowed on the social and economical effort of the community that will benefit from the project, and this must be balanced with the contribution of Van Marrewijk (Van Marrewijk, 2008) who considers the project financing as one of the most important aspects in any mega-project, because it is difficult to find a consortium of private lenders willing to assume all the risks associated with the financing of this kind of events.

This context creates the right dominion to develop a unique methodology to cope with the positive and negative impact of stakeholders in the project that (as EXPO 2015) must be financed by private companies, public administrations and final consumers. 


\section{Optimistic estimations: literature review}

In the literature, several studies indicate that optimism in the estimation of demand and costs in large projects is a common characteristic, especially in the conceptual phase of the project. In particular:

Pickrell (Pickrell, 1992) analyzes the differences between budget demand and actual demand, using a sample of eight major projects in rail infrastructure (heavy and light) in the United States. The results of his work show that in seven out of eight cases the actual demand was lower by $50 \%$ than budget, and only in one case did this difference reach "only" $28 \%$. He argues that this difference is due to inaccurate data or models.

Some researchers (Skamris et al., 1997; Trujillo et al., 2002) analyze large urban infrastructure to identify a range of variation of estimates of demand for these projects. Both researches provide similar results: the demand is overestimated by $25-60 \%$ and $20-60 \%$.

Among all the authors Flyvbjerg is probably the most relevant for this topic (see for example Flyvbjerg, 2006; 2007). His studies are based on a larger sample of infrastructure projects including 258 major projects completed over the past 70 years, in 20 different countries, for a total value of 90 billion dollars. Flyvbjerg uses this database providing many important results summarized in the following references: (Flyvbjerg et al., 2003) shows how the availability and reliability of data on large projects affects the estimation. Projects with reliable data can be managed better than average, achieving better results. The authors also argue that, usually, the decision to implement the project is made before the formal decision, consequently the early estimates are the worst.

(Flyvbjerg et al., 2005), tries to quantify the accuracy of the estimation of demand for rail and road projects. By analyzing a sample of 183 road projects and 25 rail projects, he discovers that the actual traffic of passengers in a rail project is overestimated by $105.6 \%$. For road projects, however, the actual traffic of vehicles is $9.5 \%$ higher than estimated. The authors note that the inaccuracy of estimation is not specific to a given country and it is constant over 30 years.

These contributions are strategic for a mega event because their economic impact can be catastrophic for the companies involved and for those countries that consider a mega event as a way to open their boundaries to the worldwide community, like the past Olympic Games or the coming World Soccer Cup in South Africa.

Following this approach in the international literature, two macro-categories of causes have been identified to explain these remarkable poor results:

- inadequacy of the methodologies,

- strategic data manipulation.

Inadequacy of the methodologies used

Quinet (Quinet, 1998) identifies three sources of errors: methodological problems in the structure of the model estimation, problems in the data used in the analysis, uncertainty about the values of the exogenous variables.

Trujillo (Trujillo et al., 2002) argues that estimation techniques are the main cause of differences between budget and actual values. However they include in "techniques for estimating" not only the methods of estimation of future demand, but also the methods used to derive and analyze the trend demand.

Flyvbjerg (Flyvbjerg et al., 2003) shows that it is not the model that accounts for most of the differences, but the basic assumptions made by analysts before applying the model, and later he points out that technical explanations are to be excluded because not confirmed by the data (Flyvbjerg et al., 2005). Two reasons support this argument:

- if the inaccuracy depended exclusively on technical causes, a normal distribution of error with an average close to zero should be expected, however the actual distribution is not normal with an average error much greater than zero (actual costs are usually over budget) 
- it is reasonable to expect an improvement over time of assessment methods due to more sophisticated forecasting models and modern informatics tools. However, over time, the estimations do not improve. Since technical factors do not justify the inaccuracy, authors focus on the second set of reasons.

Strategic data manipulation

Wachs (Wachs, 1990) interviewing government officials, consultants and planners in charge of different projects for transportation in the U.S., noted that estimations were biases. Planners, engineers and economists manipulated forecasts to achieve values, not justified in technical terms, but acceptable for their superiors to implement the project. Wachs hypothesizes that this abuse is "almost universal" when forecasting assumes an important role in the political debate.

Trujillo (Trujillo et al., 2002) assessed the role played by different players, both public and private, in large-scale public transport projects. They found that when a project is not entirely public the estimation and decision making process is fragmented among different players. In this case, politicians have incentive to overestimate the demand, to take political advantage when announcing new public projects.

Lovallo and Kahneman (Lovallo and Kahneman, 2003) show that cognitive biases and organizational pressures push managers to provide optimistic forecasts. They overestimate the benefits of a project and underestimate the potential hazards.

Flyvberg (Flyvberg et al., 2003; 2005), incorporates the results of previous contributions adding other reasons:

- Opportunism. This reason explains the phenomenon in terms of personal and public interest. In the first case, the project implementation should provide profits for engineers, construction companies, etc. If these players are involved in the estimation process they could bias the results in order to increase the chances of implementing the project. In the second case, the public players underestimate the costs or overestimate the demand to make the project more attractive for private investors and acceptable by society.

- Optimism bias. The authors indicate that the most common psychological explanation is the presence of a certain "optimism" which induces promoters to consider each assumption positively. The authors point out, however, that such optimism is misleading for the promoters themselves, and not an intentional error. 


\section{Method: the SHAMPU approach in EXPO 2015}

Since in this kind of event the risk of demand overestimation is quite common, it is necessary to set up a rigorous process in order to face this risk. The literature presents many risk models, and in (Haghnevis and Sajedi, 2006) there is the comparison among the most relevant. The result is that the SHAMPU (Chapman and Ward, 2003) and PMBOK (PMI, 2004) approaches result the more adequate for this context as equally stressed in (Seyedhoseini and Hatefi, 2010). Since SHAMPU is particularly appropriate when stakeholders are a major source of uncertainty in projects (Ward and Chapman, 2008), as in the EXPO 2015 case, the SHAMPU methodology seems to be the best for the EXPO project among whose main stakeholders are the visitors.

The SHAMPU methodology being an excellent framework for this analysis, we adopted it to deal with the risk of demand in EXPO 2015; the nine steps of the SHAMPU framework are addressed in the following paragraphs:

SH 1 Defining the project, see par. 3.1 and par. 3.2.

SH 2 Focusing on the project, done by the EXPO organizer committee.

SH 3 Identifying the issue, see par. 2.

SH 4 Structuring the issue, see par. 3.3.1.

SH 5 Clarifying ownership, see par. 3.3.2.

SH 6 Estimating variability, see par. 4.

SH $7 \quad$ Evaluating implications, see par. 4.

SH 8 Harnessing the plan (in this case mitigation actions), see par. 4.2.

SH 9 Managing implementations.

In order to apply the SHAMPU approach, the main data derive from the bidding document where the project is clearly defined, focused upon and different issues are proposed [SH 1, SH 2, SH 3]. To structure the issue and clarify the ownership, historical data on previous EXPO's has been merged with the approach used by the organizer [SH 4, SH 5] to identify a possible range of variability of the interested factors [SH6] along with their impact on the Project Balance [SH 7] in order to determine the mitigation plan [SH 8] and its possible management [SH 9]. To simplify comprehension the reference to the SHAMPU i-step will be indicated [SH i].

\subsection{EXPO 2015. The next mega-project in Italy}

In this section, after a brief introduction to the SHAMPU implementation in EXPO 2015, the focus will move to the analysis of the number of visitors and its impact on the Project Balance (PB) computation the actual assumptions. The last part is related to the "what-if analysis" for the development of the mitigation plan for that case, and a general discussion of the results for the methodological conclusion of the analysis.

\section{$\underline{\text { Brief introduction }}$}

On March the $31^{\text {st }} 2008$ the Bureau of International Expositions (BIE) decided that the "Universal Exposition 2015" would be held near Milan from May the $1^{\text {st }}$ through October the $31^{\text {st }} 2015$.

The theme will be "Feeding the planet, energy for life", consequently the exhibition will be focused on the various aspects connected to food and nutrition.

The site for the exposition is located in Rho - Pero in the north-west of Milan next to the "Fiera Milano" the Milan large-scale exhibition centre. Years ago the site hosted industrial plants, nowadays it is partially an agricultural area and partially hosts logistic services. The EXPO area $\left(1.38 \mathrm{Km}^{2}\right)$ is divided into Pavilions (accounting for 50\% of the space), an external area (35\%) and a green belt (15\%) [SH 1]. 
The overall projects related to EXPO 2015 can be divided into two main categories [SH 2]:

Direct Projects: all the projects (mainly infrastructural) included in the budget defined in the application phase by the Candidacy Committee. "EXPO 2015 SpA" is in charge of these projects. They are directly related to the EXPO and financed with the EXPO's funds. Such funds are necessary to finance the structures within the exhibition site, the infrastructures for connection to the site and the hosting structures.

These projects in the application are quoted as "essential" for the event (e.g. Halls, Village EXPO, Auditorium, etc.). Direct investments amount to 4.12 billion euro, representing one quarter of total forecasted budget $(25.3 \%)$.

Indirect Projects: all the projects (mainly infrastructural) related to the EXPO, but not included in the budget defined in the application phase by the Candidacy Committee. "EXPO 2015 SpA" is not in charge of these projects, since each one has already its ownership. The implementation of these projects is necessary beside the EXPO (they are infrastructural projects required for the development of the area). In some cases the projects are already in the early phases. These projects were already planned and designed before the candidature of Milan, financed with funds not allocated to the EXPO and not necessarily on the exhibition area of the site (e.g. Bre.Be.Mi.), but in the north of Italy. These projects (listed as "related" in the application documents) are useful and functional for the performance and the success of EXPO, but not strictly necessary (e.g. Pedemontana, subway M4 and M5, road Rho-Monza, etc.). These indirect investments amount to 12,2 billion, representing $74.7 \%$ of the total forecasted budget.

Overall, therefore, the investment is 16.3 billion euro.

\subsection{Cash- flow analysis with the current assumptions}

The purpose of this section is to focus on the cash flows in order to understand the sustainability of the project, distinguishing between infrastructural investments and cost-operating revenues, and then deriving the project balance.

On the basis of the previous paragraph the investments considered are those related to the direct project only with the distinctions: National Public, Local Public and Private Investments.

All the available data presented in the bid dossier have been analyzed in order to understand the main criticalities from the economic sustainability point of view and to identify the sources of potential risks for the project [SH 3]. As can be noted in Table 4, since most of the revenue is generated by "ticket selling" and the type of cost declared could be difficult to reduce, the analysis moved along the number of forecasted visitors.

Figure 1 shows the Budget Cost Work Scheduled (BCWS) for the three main players from 2009 to 2015 identifying the window 2012-2014 as the most critical in terms of financial exposure. Until 2015 the capital account revenue (equal to the expenditure) accounts for the most, since the operational costs/revenues are negligible. In 2015 the ratio changes because the greater part of operative costs/revenues occurs during the EXPO. In the period 2009-2014 the costs are slightly higher than the income, whereas in 2015 it is the opposite. In the years 2009-2014 the cost are greater than the revenues, however the sum of all the cash flows is equal to zero since in 2015 the revenues are greater than the costs. A more meaningful evaluation is performed using the Project Balance. With this methodology the final value is always negative, even with a small discount rate $(-16,7$ million of Euros with a discount rate of $3 \%,-26,3 \mathrm{M} €$ with a discount rate of 5\%,-59,8 $\mathrm{M} €$ with a discount rate of $10 \%$ ). This is the consequence of having a negative cash flow for 6 years and a positive cash flow only in the last year.

INSERT FIGURE 1 HERE 


\subsection{The estimation for EXPO 2015}

\subsubsection{Why the estimation seems optimistic}

The weakness of the EXPO 2015 financial plan emerged in the previous financial point risk analysis, is clarified in Table 4 , which shows that $60 \%$ of revenues comes from ticket sales. Since ticket sales depends on the number of visits, it can be considered the key indicator of the success of this event (from now on we consider a visitor that visits the site $\mathrm{n}$ times as $\mathrm{n}$ visitors), so a detailed analysis of the previous EXPO's with their own specific characteristics have been developed [SH 5].

From London in 1851 to Seattle in 1962 the number of people rose from 6 to 41 million, with the highest value of 45 million to New York in 1939. In each past EXPO, the way data was used to determine the forecasted future visitors was different. The main difficulties in this analysis have been the data screening, not for the availability of the data, but for the continuously changing environmental conditions of the EXPO on the basis of the localization of the exposition, the particular period of time, the logistic infrastructure, the cultural progress and involvement of communities, and so on. Too many detailed considerations can be taken into account in order to consider the previous edition, but in such a situation of uncertainty the fewer the categories the data is broken down into, the more a systematic picture of the project becomes useful.

In this case, the number of visitors has been obtained by identifying 3 different geographical areas:

Area 1: bounded by a maximum travelling time of about three hours by car or by train;

Area 2: day trips are short by plane, so the remaining Italian Regions and Europe as a whole are taken into consideration, except for Russia;

Area 3: the rest of the world.

Each area has been developed with a different model, probably too detailed. In fact, if we look at the later EXPO editions the number of visitors went decreasing, with actual values often far below the forecasts. The analysis of the estimated visitors respect to the various EXPOs is synthesized in Table 1.

\section{INSERT TABLE 1 HERE}

There is often either a significant overestimation or underestimation of visitors. In particular for European EXPO there is a significant overestimation, especially in the case of Hanover (-53\%) and Lisbon (-33\%, even if this was a specialized and not an universal EXPO). On the opposite "Aichi EXPO 2005" obtained a great success, with 22 million visitors expected against the 15 forecasted, with an underestimation of the visitors $(+46 \%)$.

The number of visitors expected in 2010 for Shanghai, 70 million, seems reasonable; in fact, in Shanghai the potential domestic visitors are more than 400 million, and Continental (area Eastern Asia), over 1,5 billion. Therefore, considering the Aichi EXPO, it is reasonable to expect a greater number of visitors for Asian EXPO respect to the European EXPO, even considering a different cultural approach to this type of event. Data suggest that the significant difference in estimated visitors between the two Asiatic exhibitions mainly depends on the size of the pool of potential domestic visitors. Domestic visitors in Shanghai are four and a half times Aichi, while the pool of potential Continental visitors is approximately the same.

On the contrary, for the Milan Expo, the estimate of 29 million visitors seems to be optimistic for three different reasons:

A: the report submitted to the BIE shows that the estimate of visitors was made by referring to two events: the Seville EXPO in 1992 and the Winter Olympics in Torino in 2006. Both these references are difficult to take into consideration since the 23 years elapsed between the Seville EXPO and Milan EXPO seem too far apart (Mazzeo, 2008). Moreover, the Sevilla'92 Expo is an exception in terms of visitors, having a record of 41.5 million visitors (this value is significantly different from previous and following EXPO's). Regarding Torino, even if the country is the same, the type of exhibition is too different to compare their respective appeals. Torino in 2006 is more recent and closer to Milan, however the Winter Olympics is an event with a much shorter duration and a completely different type 
of attractiveness and potential visitors. Even if in another country, it would be better to consider the more recent Expo's as Hanover in 2000 (with an actual value of 18 million of visitors respect to the 39 estimated).

B: overestimating is praxis. Many fewer visitors than expected attended the previous European exhibition, in particular for Hannover but also for Lisbon. According to Montanari (Montanari, 2002) an EXPO is no longer able to attract the attention of the European public (much consideration must be given to the different cultural background respect to oriental people). The author gives the example of Hannover mainly attended by inhabitants of the Land of Lower Saxony and ignored by other Germans. Mazzeo (Mazzeo, 2008) correctly argues that in the last editions the number of visitors to the EXPOs declined for two reasons: first, the saturation of the physical limits of capacity for this kind of events and, second, the use of new communication technologies to connect people with events and products. Participation was more important in the past since the physical contact was a key factor for the success of a product; nowadays, media and multimedia tools allow for the knowledge of goods and products without physical contact.

C: Milan EXPO has a number of potential domestic visitors (which account for the most) fewer than Hannover. Nevertheless, the number of expected visitors is more than $50 \%$ greater than those recorded in the German edition. This general view of the situation stresses the importance of the domestic visitors and reinforces the focus on the high risk of overestimation.

\subsubsection{Risk ownership clarification (SH 5)}

The conclusions of the preceding paragraph support the analysis of the impact of a visitors overestimation in order to breakdown the corresponding ownership and to structure an adequate mitigation plan to be coordinated by the multiple stakeholders of the project. As previously said, focusing on the direct investment the lower visitor numbers obviously impact on costs and on revenues of both the infrastructural budget (accounting for 80\% - 3,2 billion) and operational budget (accounting for 20\% - 0,9 billion).

This breakdown reflects the organizational structure of EXPO 2015 SpA based on two different Business Units (BU's): one for the infrastructural projects and the other for the operational projects (services). For this reason the detailed breakdown of these accounts seems to be very useful.

\section{Infrastructural Budget}

The analysis of the infrastructural budget results in the breakdown reported in Table 2, the in-flow and out-flow of investment cash is evidenced.

\section{INSERT TABLE 2 HERE}

\section{Operational budget}

The operational budget includes the sponsorship of the event, promotions, ticket sales, rents etc. According with the business plan in the bid dossier, the operating costs for the management and organization are fully covered by operating revenues, therefore costs and revenues are equal to 892 million Euros.

The cost breakdown is summarized in Table 3, while the revenues breakdown is summarized in Table 4 . As regards revenues, it is evident that ticket sales will account for most. If fewer visitors attend the event, the "EXPO 2015 SpA" Business Unit will have a strong impact on project profitability. Therefore this Business Unit is the main owner of this risk and is in charge of setting up an appropriate risk management process. Table 4 reinforces the assumption of the critical forecast for the number of visitors since it covers $60 \%$ of the revenues of the direct project.

INSERT TABLE 3 and 4 HERE 


\section{Results of the overestimation: how to deal with it}

\subsection{Effect on the project Balance}

To estimate a reasonable variability (SH 6) a scenario analysis has been developed changing the number of visitors and re-computing costs and revenues with related impact on Project Balance, identifying the relation between the causes and the effects of this factor.

Certain values are independent from the number of visitors, (e.g. roads), others are proportional (linearly or not) to the visitors (e.g. revenues from the tickets).

The following scenarios have been tested:

- Very Pessimistic estimate: 18 million visitors (about 40\% less than the bid estimate). This is the number of visitors in Hanover in 2000, the last European EXPO.

- Pessimistic estimate: 25 million visitors (about $15 \%$ less than the bid estimate). This estimate considers the number of visitors of Aichi 2005, the last held in Japan attended by 22 million. In the EXPO 2015 case, which will take place 10 years later, it is possible to assume a slight increment.

- Bid estimate: 29 million. Is the estimation provided in the bid dossier

- Optimistic estimate: 33 million visitors (about 15\% more than the bid estimate).

\section{INSERT FIGURE 2 HERE}

Figure 2 summarizes the 'what if analysis' ( $\mathrm{SH} 7$ ), showing the main effect exclusively on ticket sales, thus in 2015, and that under those conditions the PB in 2015 will be, most likely, negative or close to zero. Therefore planners have to come back to the project definition and variability estimation phases to tune some assumptions and to prepare a mitigation plan following the guidelines suggested in the next paragraphs.

\subsection{Possible mitigation actions}

Since the estimation of 29 million visitors for EXPO 2015, seems too optimistic, it is necessary to implement mitigation actions to overcome or minimize the impact of some critical issues related to the overestimation of the visitors, such as: budget deficit, waste of funds, over sizing of the infrastructures etc. ( $\mathrm{SH} 8$ ).

It is possible to implement two strategies:

1- Costs reduction

2- Revenues increase

\subsubsection{Costs reduction}

The main actions to reduce costs are:

Reduce the investments in infrastructure (roads, railways, metro). In the EXPO this action is very hard to apply to the main indirect projects (e.g. Bre.Be.Mi, TEM, Pedemontana) because they are necessary even without the EXPO. Moreover, other projects (e.g. Metro 5) are already in the construction phase. For direct projects (the halls, squares, logistic centres), it is not possible either to implement this action because these structures are strictly necessary for the event and the decreasing costs start to be significant only with a reduction of more than $50 \%$ of forecasted visitors, so without a real impact on the cost accounts.

Build smaller secondary facilities. The actual plan is for 17,000 parking spaces, but if visitors are fewer than expected car parks are over dimensioned. If, during the EXPO, the visitors are more than expected it is possible to implement corrective actions involving public transport companies to integrate the service. It should be noted, however, that the parking-lot is built entirely with private funding so that investors will obviously participate in the future, so a reduction here does not generate savings in public resources. 
Reduce the number of new hotels. According to Federalberghi (the Italian Hotels Association) the number of existing hotels is already enough. Part of private investment in hotels may be shifted to cheaper facilities such as hostels, university residences, etc., notoriously lacking in the area considered (around Milan) and more easily reusable after 2015.

Reduce the labour cost i.e. the volunteers and staff. The goal is to have the smallest staff necessity. Since the number of volunteers is related to numbers of visitors it is possible to decrease this number. In order to avoid lack of staff it is possible to prepare agreements with employment agencies to hire staff when necessary (as suggested by the "real options" approach). This solution was already adopted in the case of EXPO 2000 in Hanover (Montanari, 2002). However in Hannover this measure was not planned, therefore it did not generate significant savings. Another considered case was the last Olympic Games in Beijing, where the number of volunteers exceeded the forecast, but since the reason was related to cultural believes, the same algorithm cannot be applied to EXPO 2015.

\subsubsection{Revenues increasing}

The main way to increase the revenues is to increase the number of visitors and the sponsorships. Focusing on the most important (increasing the number of visitors) there are three different types of actions:

A. Advertising campaigns

B. Other Marketing actions

C. Project timing.

\section{A. Advertising campaigns}

Campaigns to promote the event can stimulate the participation of different types of visitors. These promotional activities should be directed to:

- Potential local visitors, representing usually $3 / 4$ of total visitors

- Companies, in particular those connected in some way to the theme of the exhibition. Through the EXPO they could identify new business or market share, new products, technologies or find inspiration for new business ideas.

- Humanitarian organizations and institutions (UNICEF, FAO, EFSA, etc..). They could collect and share information on food projects with economic and social institutions, universities, etc..

- It is possible to implement advertising campaigns in many ways, including:

- Television spots with celebrities, as done for Hanover 2000, even if in that case the choice was not very effective, because implemented too late, during the exhibition. In Milan, however, by using the lesson learned from Hanover, it is possible to achieve better results.

- Set up an EXPO- Observatory to assess the knowledge of the potential visitors. Having identified the deficiencies in terms of information flow, it can propose reactive actions.

Federalberghi notes that "visitors are different from tourists", therefore, to increase the flow of visitors many tourists should become visitors. Visitors have specific interests mainly related to business and often make short visits. On the other hand, tourists have more cultural and artistic interests, so even if tourists are not particularly interested in the EXPO, if properly elicited they can become visitors. EXPO should become part of the classical "trip to Italy". Therefore campaigns and promotional agreements with tourism organizations should incentivize tourists to visit the EXPO.

Some actions could include:

- the creation of centres of attraction at the EXPO (museums, tours, etc.) to attract visitors with interests not purely economic. This could be achieved through agreements with museums, theatres, theme parks etc.; 
- the creation of a network of events and strategic alliances between Milan and foreign cities (Montanari, 2002) to incentivize foreign citizen to visit the EXPO. It is wise to use the existing network and institutional arrangements;

- agreements with schools and universities proposing tours at the EXPO;

- agreements with tour operators, proposing tours of several days, based on the theme of food (e.g. visiting firms and the EXPO).

\section{B. Other Marketing actions}

It is possible to implement special policies to sell the tickets, for example:

- Creating agreements with airlines, railways, subways, to reduce the rates for direct visitors at the EXPO, or creating combined tickets travel expo + entry;

- Linking the purchasing of products from sponsors to the discounts on the EXPO tickets;

- Changing from antagonism to symbiosis with other attractions (e.g. museums, festivals, fairs, theatres) by creating combined tickets to attend various events.

- Introducing discounted tickets for college students. The plan presented in Chapter 11 does not provide for specific tickets for college students, who must pay the full rate. Only in Milan there are seven universities with 250,000 Italian students and 8000 foreign students which could represent an important market, especially in the process of Internationalization that most Milan Universities started few years ago.

It would be hard to reduce the general price of the ticket, as was the case of the Hannover EXPO, when the price dropped from 24 to $15 \mathrm{DM}$ causing further losses instead of increasing the number of visitors (Montanari, 2002).

\section{Project timing}

It is important to ensure that planned projects (highways, metro, etc.) are completed in time. The completion of infrastructural projects would avoid negative messages from the media, both Italian and foreign, as already happened in the case of the Jubilee in Rome in 2000.

Regarding the last phase of the SHAMPU approach (manage implications - SH 9) there is no detailed approach in the official documentation, since a rolling wave approach in risk management is generally declared during the project execution. But this consideration brings to interesting discussions, both from the real case study and the methodological point of view, that will be exposed in the next paragraph. 


\section{Conclusions and further developments}

This paper deals with the risk of optimistic overestimation in mega-events during the planning phase proposing a framework to plan the next mega event in Italy: the 2015 Universal Exposition "Milano 2015"

The paper summarizes the literature showing that optimistic estimation is a common mistake in the planning phase of mega-projects. During the planning phases the biases optimism is used to delineate a scenario favorable to whom is willing to implement the project. One of the main negative consequences of this attitude is the reduction of the final value of the project. In order to avoid this output, it is necessary to implement a risk management methodology before the events start.

A literature review shows that there are a lot of approaches to risk management; they are usually based on construction projects (since their technical difficulties can greatly impact on the project execution). Regarding mega-events like the EXPO, the critical factors emerging from this research is the importance of a right forecast of the number of visitors (which provide $59 \%$ of the revenue) in order to size the infrastructure and the amount of human resources necessary to perform the event. Visitors are project stakeholders, therefore, to handle this risk it is necessary to implement a risk-management approach focused on the stakeholders; the literature presents the SHAMPU methodology as the best choice for stakeholders risk management. Therefore the SHAMPU approach is used to analyze the EXPO 2015 project and to propose the practical actions to achieve the best results.

At this stage of the project, to use complicated algorithms to estimate the number of visitors can be misleading. In fact, complicated algorithms require a lot of detailed information not available at the moment, allowing at the same time, for data manipulation to present results required by whom is willing to implement the project. As Flyvbjerg proposes, it is wiser to use actual data from the most recent similar previous projects (in this case the Hannover EXPO) to forecast the values for the project under analysis. Following this approach in the SHAMPU process, the paper presents different scenarios.

The result, is that, with the current expected cost, the EXPO 2015 terminal value, most likely, will be negative. For this reasons it is necessary to plan in advance the actions to both increment the revenues (mainly incrementing the visitors) and to reduce the costs. But in the EXPO project, an evident missing element (in the costs and revenues accounts) is the increasing economic value of the area after the EXPO. Nowadays, as said in the introduction, the area is principally agricultural while after the construction of the logistic infrastructure for the EXPO, the area will be easily transformed into a residential one. This element is not included in the analysis, but can be easily evaluated in a possible income of $25 \mathrm{M} €-35 \mathrm{M} €$ that, considering the possible variance of the project balance exposed in Figure 2, can greatly change the picture of the economic profile of the event.

This technical consideration on the case study also suggests a methodological review of the SHAMPU approach that could be seen as a further step of the analysis: [SH 10] analyze dismissing consequences: evaluate all the consequences in the short and long term of the project quantifying strategic returns. This analysis must be connected with a secondary feedback loop to the first phase of the SHAMPU methodology [SH 1] in order to avoid possible under or overestimations of the returns on the project.

Considering as an example the construction of a subway, a public administration does not implement such projects to generate revenues (as private sectors does), but to provide the necessary development for a certain area. This opens a huge research stream connected to risk management and to the application of the SHAMPU approach to mega-event. 


\section{References}

To perform the analysis we mainly referred to the "bid dossier" submitted to the BIE and available at http://www.milanoexpo-2015.com.

- Bruzelius, N., Flyvbjerg B. and Rothengatter W. (2002) 'Big decisions, big risks: improving accountability in mega projects', Transport Policy, Vol. 9, No. 2, pp.143-154.

- Chapman, C.B. and Ward, S.C. (2003) Project risk management: Process, techniques and insights, Second Edition, Chichester: John Wiley and Sons.

- Clegg S, Pitsis T, Rura-Polley T, Maroosszeky M. (2002) 'Governmentality matters: designing an alliance culture of interorganizational collaboration for managing projects', Organ Studies, Vol. 23, No. 3, pp.317-38.

- Flyvbjerg B. (2007) 'Policy and planning for large infrastructure projects: problems, causes, cures', Environment and Planning B: Planning and Design, Vol. 34, No. 4, pp.578-597.

- Flyvbjerg, B. (2006) 'From Nobel Prize to project management: getting risk right', Project Management Institute, Vol. 37, No. 3, pp.5-15.

- Flyvbjerg, B., Bruzelius, N., \& Rothengatter, W. (2003) Megaprojects and risk: An anatomy of ambition Cambridge, Cambridge University Press.

- Flyvbjerg, B., Holm, M. K. S., and Buhl, S. L. (2002) 'Underestimating costs in public works projects: Error or lie?', Journal of the American Planning Association, Vol. 68, No. 3, pp.279-295.

- Flyvbjerg, B., Holm, M. K. S., and Buhl, S. L. (2005) 'How (in)accurate are demand forecasts in public works projects? The case of transportation.' Journal of the American Planning Association, Vol. 71, No. 2, pp.131-146.

- Haghnevis, M., and Sajedi, H. (2006) 'A model for assessment of project management risk models'. Paper presented at the $4^{\text {th }}$ International Management Conference, December, 2006. Tehran, Iran.

- Lovallo, D., and Kahneman, D. (2003) 'Delusions of success: How optimism undermines executives' decisions', Harvard Business Review, Vol. 81, No.7 pp.56-63.

- Mazzeo G. (2008) 'Great Events: Indicators for Classification and their Impact on the Urban Systems' TeMAlab, Vol. 1, No. 2, p.. 77-86.

- Montanari A. (2002) 'Grandi eventi: marketing urbano e realizzazione di nuovi spazi turistici', Bollettino della Società Geografica italiana, Serie XII, Vol. VII, pp. 757-782. (Italian Language).

- Pickrell D H. (1992) 'A desire named streetcar fantasy and fact in rail transit planning', Journal of American Planning Association, Vol. 58, No.2, pp.158-176.

- PMI (2004) A Guide to the Project Management Body of Knowledge (PMBOK® Guide) - Fourth Edition

- Quinet E. (1998) Economic principles of transport, Paris: Economica.

- Seyedhoseini, S.M., and Hatefi, M.A. (2010) 'Two-Pillar Risk Management (TPRM): A Generic Project Risk Management Process'. International Journal of Science and Technology, article in press, downloadable from www.scientiairanica.com/PDF/Articles/00000692/65.174.doc

- Skamris Holm M. K. and Flyvbjerg B. (1997) 'Inaccuracy of traffic forecasts and cost estimates on large transport project', Transport Policy, Vol. 4, No. 3, pp.141-146.

- Trujillo L, Quinet E, Estache A. (2002) 'Dealing with demand forecasting games in transport privatization', Transport Policy, Vol. 9, No. 4, pp.325-334.

- Van Marrewijk, S. R. Clegg, T. S. Pitsis, M. Veenswijk (2008) 'Managing public-private megaprojects: Paradoxes, complexity, and project design', International Journal of Project Management, Vol. 26 No. 6, pp. 591-600. 
- Wachs M. (1990) Ethics and advocacy in forecasting for public policy, Business and Professional Ethics Journal 9 141-157.

- Ward, S.; Chapman, C. (2008) 'Stakeholders and uncertainty management in projects', Construction Management and Economics, Vol. 26, No. 6, 2008 , pp. 563-577.

- Warrack, A.A. (1985) Resource megaproject analysis and decision making Victoria, BC: Institute for Research on Public Policy.

- Warrack, A.A. (1993) Megaproject decision making: Lesson and Strategies, Western Resources Program Number 16, University of Alberta Faculty of Business Edmonton, Alberta. 


\section{FIGURES}

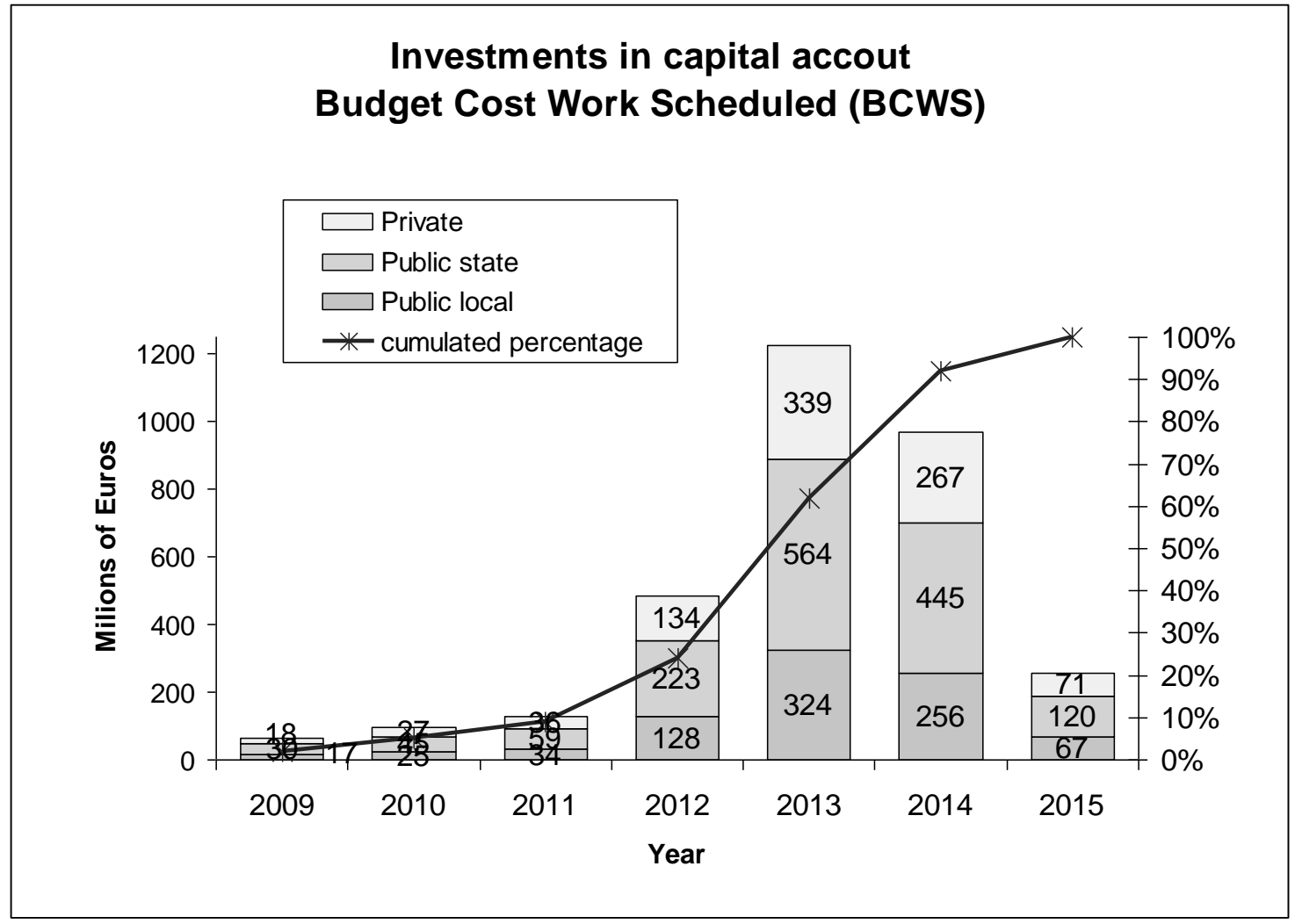

Figure 1 BCWS - Investments in capital account

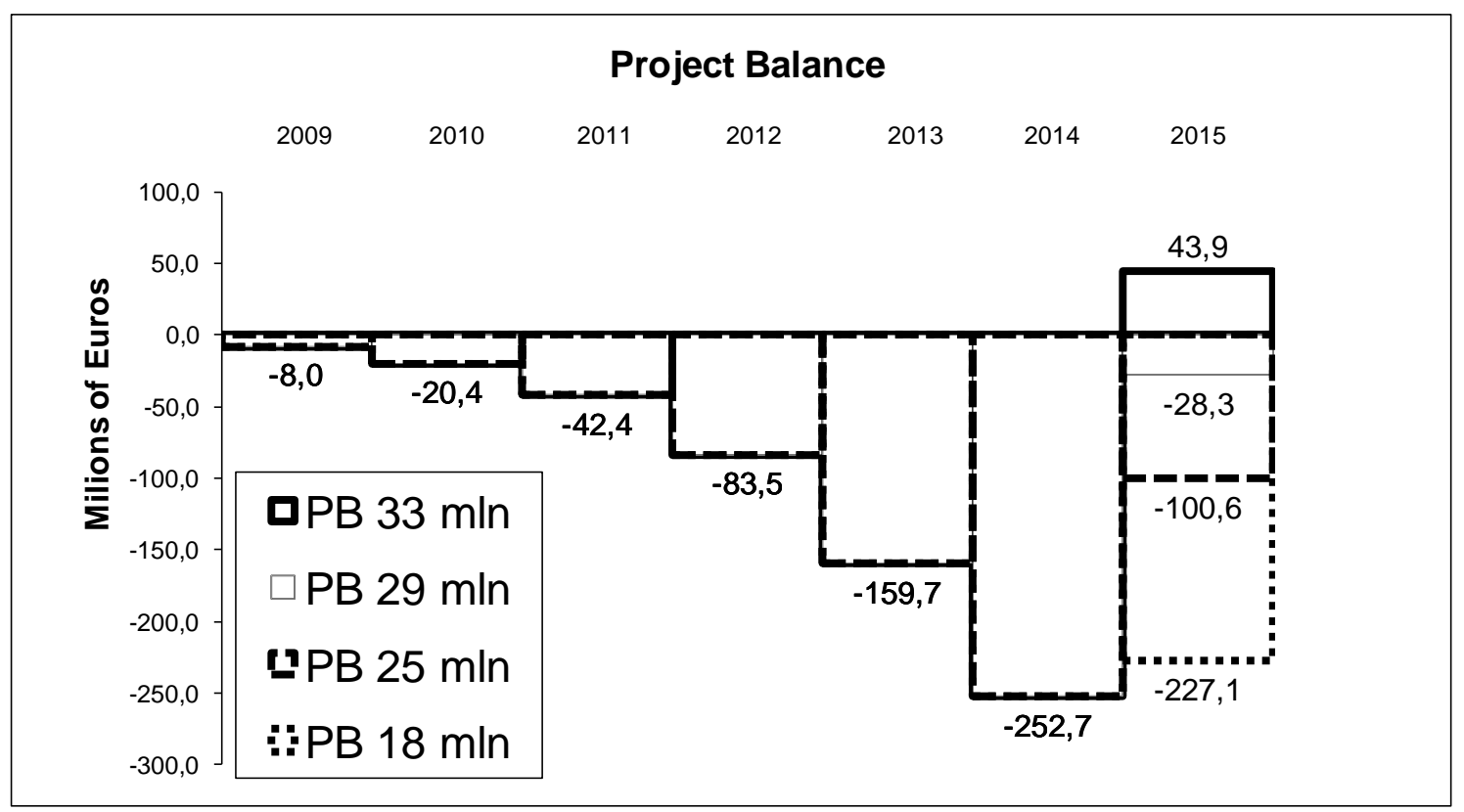

Figure 2 Project Balance according to different number of visitors. Only 2015 differs since the number of visitors mainly impacts on the operative costs and revenues. Actualization rate $=5 \%$ 


\section{TABLES}

\begin{tabular}{|c|c|c|c|c|c|c|}
\hline \multirow[t]{2}{*}{ Edition } & \multirow{2}{*}{$\begin{array}{c}\text { Duration } \\
\text { [days] }\end{array}$} & \multirow{2}{*}{$\begin{array}{c}\text { Estimated } \\
\text { Visitors } \\
\text { [mln] }\end{array}$} & \multirow{2}{*}{$\begin{array}{c}\text { Actual } \\
\text { Visitors } \\
\text { [mln] }\end{array}$} & \multirow{2}{*}{$\begin{array}{c}\text { Difference } \\
{[\%]}\end{array}$} & \multicolumn{2}{|c|}{ Potential visitors [mln] } \\
\hline & & & & & Domestic & Continental \\
\hline Milan 2015 & 183 & 29 & - & - & 29 & 534 (Europe) \\
\hline Shangai 2010 & 180 & 70 & - & - & 400 & $\begin{array}{c}1550 \text { (Asia } \\
\text { Oriental) }\end{array}$ \\
\hline Aichi 2005 & 185 & 15 & 22 & $+46 \%$ & 86 & $\begin{array}{c}1500 \text { (Asia } \\
\text { Oriental) }\end{array}$ \\
\hline Hannover 2000 & 152 & 39 & 18 & $-53 \%$ & 36 & 482 (Europe) \\
\hline Lisbon 1998 & 132 & 15 & 10 & $-33 \%$ & 13 & 478 (Europe) \\
\hline
\end{tabular}

Table 1 Estimations for the previous editions

\begin{tabular}{|c|c|c|c|c|c|}
\hline Account & $\begin{array}{l}\text { Financing from } \\
\text { private sector }\end{array}$ & $\begin{array}{l}\text { Financing from } \\
\text { the Italian state }\end{array}$ & $\begin{array}{l}\text { Financing from } \\
\text { local government }\end{array}$ & $\begin{array}{c}\text { Total } \\
\text { Investment } \\
{[\mathrm{M} €]}\end{array}$ & $\begin{array}{c}\% \text { of total } \\
\text { investment }\end{array}$ \\
\hline Site preparation & \begin{tabular}{|lll}
$46 \%$ & & \\
& 407 & \\
& & $32 \%$ \\
\end{tabular} & $\begin{array}{lll}44 \% & & \\
& 656 & \\
& & 52 \%\end{array}$ & $\begin{array}{lll}22 \% & & \\
& 190 & \\
& & 15 \%\end{array}$ & 1253 & $39 \%$ \\
\hline $\begin{array}{l}\text { Projects to } \\
\text { connect the site }\end{array}$ & 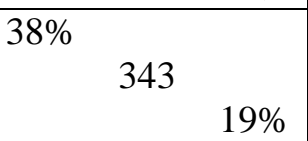 & $\begin{array}{lll}53 \% & & \\
& 786 & \\
& & 44 \%\end{array}$ & $\begin{array}{lll}76 \% & & \\
& 651 & \\
& & 37 \%\end{array}$ & 1780 & $55 \%$ \\
\hline $\begin{array}{c}\text { Accommodation } \\
\text { facilities }\end{array}$ & $\begin{array}{ll}81 & \\
& 60 \% \\
\end{array}$ & $3 \%$ & $1 \%$ & 135 & $4 \%$ \\
\hline Technology & $\begin{array}{ll}60 & \\
& 100 \% \\
\end{array}$ & $0 \%$ & $0 \%$ & 60 & $2 \%$ \\
\hline $\begin{array}{c}\text { Total } \\
\text { Investment } \\
{[\mathrm{M} €]}\end{array}$ & 891 & 1486 & 851 & 3228 & \\
\hline $\begin{array}{c}\text { \% of total } \\
\text { investment }\end{array}$ & $28 \%$ & $46 \%$ & $26 \%$ & & $100 \%$ \\
\hline
\end{tabular}

Table 2 Infrastructural budget breakdown cost - In the top left corner the percentage in the column, in the bottom right the percentage in the row 


\begin{tabular}{|c|c|c|}
\hline Account & Value (M€) & Value (\%) \\
\hline Marketing & 161 & $18 \%$ \\
\hline Entertainments at EXPO site & 133 & $15 \%$ \\
\hline Staff and human resources & 130 & $15 \%$ \\
\hline Technologies & 107 & $12 \%$ \\
\hline Other & 59 & $7 \%$ \\
\hline Service at the EXPO site & 56 & $6 \%$ \\
\hline Rent, transport, equipment & 54 & $6 \%$ \\
\hline Development programs & 52 & $6 \%$ \\
\hline Contingencies & 42 & $5 \%$ \\
\hline General service & 35 & $4 \%$ \\
\hline Insurance and financial costs & 23 & $3 \%$ \\
\hline Cooperation projects & 20 & $2 \%$ \\
\hline Surveillance & 20 & $2 \%$ \\
\hline Total & 892 & $100 \%$ \\
\hline
\end{tabular}

Table 3 Costs in the operational budget

\begin{tabular}{|c|c|c|}
\hline Account & Value (M€) & Value (\%) \\
\hline Ticket sales & 522 & $59 \%$ \\
\hline Sponsorship & 219 & $25 \%$ \\
\hline Transport and parking lots & 46 & $5 \%$ \\
\hline Pavilion Rents & 30 & $3 \%$ \\
\hline National lottery & 25 & $3 \%$ \\
\hline Merchandising and similar & 20 & $2 \%$ \\
\hline Equipment Rents & 15 & $2 \%$ \\
\hline Resell after EXPO & 11 & $1 \%$ \\
\hline Fee for restaurants & 4 & $0 \%$ \\
\hline Total & 892 & $100 \%$ \\
\hline
\end{tabular}

Table 4 Revenues in the operational budget 